\title{
BALANDÚ COMO ESPACIO SIMBÓLICO: UNA LECTURA DESDE EL MITO DEL ORIGEN*
}

\author{
BALANDÚ COMO ESPAÇO SIMBÓLICO: UMA LEITURA \\ DESDE O MITO DO ORIGEM
}

\author{
Eliana María Urrego Arango ${ }^{1}$
} Artículo derivado de la tesis doctoral
"Balandú, pueblo en vía de sueño. Universo
literario de Manuel Mejía Vallejo",
Universidad de Salamanca.

Cómo citar este artículo: Urrego Arango, E. M. (2019). Balandú como espacio simbólico: una lectura desde el mito del origen. Estudios de Literatura Colombiana 44, pp. 117-131. DOI: https://doi.org/10.17533/udea.elc.n44a07

${ }^{1}$ eliana.urrego@upb.edu.co

Universidad Pontificia Bolivariana, Colombia

Recibido: 15.08 .2018

Aprobado: 18.10.2018
Copyright: $\odot 2019$ EstudiosdeLiteratura Colombiana. Este es un artículo de acceso abierto distribuido bajo los términos de la Licencia Creative Commons Atribución No comercial - Compartir igual 4.0 Internacional
Resumen: Balandú es un espacio ficcional creado por Manuel Mejía Vallejo, inspirado en su pueblo Jardín. Este mundo imaginario, al igual que otros más reconocidos como Macondo, se estructura como una geografía simbólica y toma el lugar de un mito. Este artículo, producto de una investigación sobre el tema, presenta una lectura de dicha aldea literaria a la luz de las teorías antropológicas del imaginario, que permiten entender su importancia como uno de los espacios simbólicos y míticos de la literatura andina colombiana.

Palabras clave: espacios imaginarios; Manuel Mejía Vallejo; Balandú; mito.

Resumo: Balandú é um espaço ficcional criado por o escritor Manuel Mejía Vallejo inspirado em seu povo Jardín. Este mundo imaginário, junto a outros mais reconhecidos como Macondo, estrutura-se como uma geografia simbólica e adota as características do mito. Este artigo, produto duma investigação sobre o tema, expõe uma leitura desta aldeia literária desde as teorias antropológicas do imaginário, permitindo entender sua importância como um dos espaços simbólicos e míticos da literatura andina colombiana.

Palavras-chave: espaços imaginários; Manuel Mejía Vallejo; Balandú; mito. 
Algún día volveré a Balandú en busca de mis pasos perdidos. Algún día subiré al páramo donde inventamos la lluvia

Manuel Mejía Vallejo

La obra de Manuel Mejía Vallejo puede compararse con un gran tejido en el que cada hebra se entrelaza con otras de caminos diversos, las historias son muchas pero todas trabajan por construir una sola imagen que las contiene y las organiza. Dicha imagen es Balandú, un pueblo imaginario que en ocasiones es el centro de los relatos y en otros es el espacio de los sueños y las nostalgias. Balandú es la patria de todos los seres creados por el escritor antioqueño, es el lugar de donde un día se parte y al que algún día se ha de regresar. La aldea es esa labor que ocupó durante años en el telar de la narración a un hombre que quiso perfilar allí los símbolos y actuaciones de un pueblo andino, y en la que eligió con cuidado y dedicación entramados, colores y fibras, hasta conseguir un paño en el cual la metáfora es imagen total. Siguiendo una tradición que parte de la Yoknapatawpha de Faulkner y se consolida con el Macondo de García Márquez, Balandú se inserta dentro del contexto de las letras latinoamericanas como un espacio donde la creación literaria consigue dar luces mucho más allá de una apreciación descriptiva de lo geográfico al proponer una mirada simbólica del territorio.

Para abordar un mundo de ficción como Balandú, que abarca varias novelas y está presente en más de la mitad de la producción de un autor, es necesario entender de qué manera esta aldea se convierte en geografía imaginaria y es elevada a imagen mítica que ordena el cosmos. Se reconoce que este tipo de topografías narrativas trascienden el escenario y poco a poco consiguen representar el sentir y el ser de las personas o incluso de los pueblos, convirtiéndose en espacios simbólicos. Dentro de la narración de estas comarcas podemos encontrar diversos niveles espaciales, tal como plantea Cassirer (1963, p. 71), entre los cuales se hallan un espacio orgánico en el que habitan los personajes y las cosas, un espacio perceptivo descrito a través de la información óptica, olfativa, táctil, acústica y kinestésica de los mismos personajes, y un espacio abstracto que apunta a un lugar que es representado, que no es ni lo que se percibe ni donde se acciona, sino una concepción del orden cósmico, una abstracción de la realidad. En este marco es posible entender a Balandú como representación, como un espacio que, si bien está conformado por el nivel orgánico y perceptivo, llegaría hasta el nivel simbólico, anclando allí su función principal. En otras palabras, Balandú no se propone nombrar lo sensible, sino lo no-sensible, lo que está ausente y 
no se percibe, lo inconsciente, lo metafísico, lo espiritual. Es un pueblo que emerge como imagen simbólica, entendiendo símbolo con Durand (1971) como "la mejor representación posible de la cosa relativamente desconocida, que por consiguiente no sería posible designar en primera instancia de manera más clara ni más característica" (p. 13). Balandú no es entonces una alegoría de un pueblo, sus elementos se componen como imagen simbólica, es decir, la aldea imaginaria es representación que se carga de sentidos y solo vale por sí misma, pues no puede comprobarse lo que significa, es inalcanzable el sentido de su significado.

\section{Balandú en la imaginación simbólica}

Nuestra aldea es pensada como la encarnación de algo más que un pueblo real, es un intento de nombrar diversos sentidos que no pueden ser aprehendidos y que reaparecen constantemente como interrogantes de la cultura. Nace de querer capturar "el alma" de un poblado en una imagen (un significante). Este proceso de creación demanda a su autor la actitud de un demiurgo. Mejía Vallejo reúne todas sus posibilidades creativas para dar origen a una serie de novelas y relatos que narran la vida en un pueblo de cordillera. El carácter de los hombres de montaña no es el mismo de quienes están a la orilla del mar, la construcción de un pueblo en un monte selvático demanda tenacidad y trae consigo muchos riesgos; la vida es entendida desde esta perspectiva de la altura, la distancia y la dificultad de los caminos. El autor de Balandú quiere recoger sus vivencias de infancia y juventud en un pueblo de Antioquia, ${ }^{1}$ siente la necesidad de ordenar los recuerdos de otros a quienes ha escuchado por años, su familia, sus vecinos; hay en él una emergencia de dejar constancia del mundo conocido antes que el tiempo pase y no quede memoria de él. Para lograr su propósito, configura una geografía imaginaria, funda un espacio, cuenta su origen, crea un contexto para la realidad de sus personajes y un marco referencial para narrar una leyenda. El pueblo imaginario es la simiente sobre la que se edifica toda la narración, pues al llevar estos parajes conocidos a la ficción, el autor espera poder hilar todo el conjunto de conocimientos y experiencias, recrear la existencia en ese lugar específico del mundo y erigir una memoria. La novela será

1 Mejía Vallejo se inspira en la región del suroeste de Antioquia, específicamente en Jardín, su pueblo natal, para dar vida a Balandú. Proceso común entre los creadores de aldeas imaginarias, pues encontramos que Onetti lo hace con Buenos Aires, García Márquez con Aracataca y Rulfo con varios pueblos de Jalisco. Como en todos estos casos, en Balandú se reflejan elementos que abarcan la geografía de un territorio trascendiendo la condición específica de la aldea. 
el tipo de texto requerido para construir estas aldeas imaginarias; aunque encontremos cuentos que se ubican en dichos espacios, es en la novela donde se consigue crear todo el entramado de historias, tiempos y personajes que reclama la complejidad de estos mundos. Además, la novela, como señala Cortázar (1994), “es el instrumento verbal necesario para el apoderamiento del hombre como persona, del hombre viviendo y sintiéndose vivir" (p. 223). En el momento histórico en el que aparece Balandú, segunda mitad del siglo $\mathrm{xx}$, el escritor de novelas "tiende a descartar toda búsqueda de esencias que no se vinculen al comportamiento, a la condición, al destino del hombre y, lo que es más, al destino social y colectivo del hombre" (p. 234). Esta búsqueda del sentir humano es el punto en el que Balandú y los universos imaginarios semejantes se hacen universales. Demuestran que los hombres comparten una suerte similar, y lo hacen a través de diseñar unos modos de ser, una organización de valores, creencias y explicaciones propias que reivindican el derecho a la diferencia, que inscriben lo peculiar en el registro de la condición humana y lo alejan de la descripción folclórica.

La intención de mostrar el ser del antioqueño queda plasmada en Balandú más allá de las imágenes típicas del cafetal y el arriero con su indumentaria de carriel, machete y mula. Mejía Vallejo no quiere dibujar lo típico de la región andina colombiana, su interés es desentrañar las preguntas más profundas del alma antioqueña, para lo cual presenta a los personajes de una familia, cuyo destino transcurre al amparo de su apellido y, por tanto, de las decisiones de sus ancestros: "Dios nos maldijo, estaba escrito que serían desgraciados los descendientes" (Mejía Vallejo, 1980, p. 7). Esta es una característica común de tales creaciones, en las que los vínculos familiares, con todos sus conflictos, son un punto clave para dar cuenta de la realidad espiritual de los personajes. ${ }^{2}$ Además, al narrar el contexto donde se producen estas formas de relación familiar, se reflejan los fundamentos de la cultura.

2 Podemos encontrar que este elemento es común en las aldeas literarias más reconocidas de Latinoamérica. El viaje hacia Comala comienza con una promesa a la madre y la búsqueda del padre que los ha abandonado, a la par que se muestra la complejidad de las relaciones que establece Pedro Páramo con el pueblo en general. Asimismo, los cien años de Macondo están directamente relacionados con la genealogía, elemento que le da un carácter épico a la narración, y permite dibujar una visión casi etnográfica de la tradición cultural. En Santa María, la cuestión de los vínculos se plantea en otro sentido, en la vida de la ciudad portuaria donde la familia está desdibujada, a estos personajes no les alcanza el apellido para armar su identidad, son viajeros, proxenetas, exiliados, inmigrantes que día a día luchan por consolidar su arraigo a la realidad que los rodea. Se evidencia así el reflejo de las constantes migraciones y exilios que se vivieron en el sur del continente hasta las últimas décadas del siglo xx. 
Encontramos que a través de la familia Herreros se puede entender la dinámica de situaciones como el poder que tiene un fundador sobre un pueblo; el apego a la tierra; el conflicto de la iglesia católica con los procesos de modernización; la convivencia sincrética entre la moral católica, la magia y los seres imaginarios de la tradición indígena y campesina; las explicaciones de la realidad que se suceden de generación en generación; las formas permitidas y no permitidas del amor; la importancia simbólica de las casas familiares; cuándo y de qué forma se practican la fiesta, la celebración y el duelo. Pareciera que la novela está más del lado de un estudio histórico o cultural, la información que recoge corresponde a las ciencias sociales; sin embargo, no se ocupa de la comprobación, no hay un interés en hacer del contenido algo fiable, su motivación es propiamente la narración que busca dar sentido a las impresiones y silencios de la historia al permitir la reescritura de lo que ya ha acontecido. La ficción narra aquello que la historia no puede nombrar en sus pretensiones de objetividad, y consigue versiones subjetivas de la realidad, formas de la memoria de un pueblo.

Al decir Balandú se tiene un significante concreto que refiere a significados imposibles de representar, que son inasibles. Balandú, como imagen simbólica, no es la representación de una "cosa", como la nombra Cassirer (1972), es la "cosa" en sí, pues "no solo la representa sino que opera como ella sustituyéndola en su inmediato presente" (p. 63). Esta es una de las características del pensamiento simbólico: "Siempre que se topa con algo puramente significativo, para aprehender esta significación pura tiene que transformarla en un ser o cosa" $(p, 63)$, que en este caso sería un universo imaginario. En la creación de este mundo literario intervienen las tres dimensiones concretas que posee un símbolo:

Es al mismo tiempo "cósmico" (es decir, extrae de lleno su representación del mundo bien visible que nos rodea), "onírico" (es decir, se arraiga en los recuerdos, los gestos, que aparecen en nuestros sueños y que constituyen, como demostró Freud, la materia muy concreta de nuestra biografía más íntima) y por último "poético", o sea, que también recurre al lenguaje, y al lenguaje más íntimo, por lo tanto el más concreto (Durand,1971, p. 15).

Construir espacios que contengan las dimensiones cósmica, onírica y poética lleva a transformar la observación del mundo real en uno imaginario, adentrándose así en el plano de laimaginación simbólica. Los poetas consiguen simbolizar la realidad a partir de ensoñaciones. Hay un impulso por construir situaciones irreales que den sentidos a las preguntas que preocupan en lo que concierne a lo real, tendencia que si bien es compartida por todos los seres humanos, en el escritor logra ser materializada al volverse lenguaje escrito, 
donde el hallazgo de una imagen se convierte en el germen de un espacio, el comienzo de la raíz de un mundo ficcional. Mediante las creaciones imaginarias la literatura intenta resolver los interrogantes fundamentales del ser humano, pues en la escritura o el relato oral se entiende mejor que en las percepciones sin anclaje narrativo, narrar implica escuchar las palabras con todos sus matices. Un mundo es imaginado para dar cuenta de aquello que ni la ley ni las convenciones han podido nombrar, de ahí su capacidad simbólica y mítica. A esto ha respondido la literatura latinoamericana con la creación de mundos vastos y complejos que reflejan su identidad.

\section{Balandú, una respuesta a la pregunta por el origen}

En Comala, Macondo o Balandú encontramos universos que se nutren de la riqueza del imaginario cultural de Latinoamérica, ordenados a partir de ensoñaciones relacionadas con las creencias, los ritos y las leyendas de los pueblos, para dar lugar a una recreación. Todos constituyen una imagen que varía de uno a otro, que es siempre nueva, pero que responde a la misma resonancia: la pregunta por el origen. Una cuestión que en América Latina retorna como un eco incesante. Así lo refleja Alejo Carpentier (1971) en este fragmento de Los pasos perdidos:

Fundar una ciudad. Yo fundo una ciudad. Él ha fundado una ciudad. Es posible conjugar semejante verbo. Se puede ser Fundador de una Ciudad. Crear y gobernar una ciudad que no figura en los mapas, que se sustraiga a los horrores de la Época, que nazca así, de la voluntad de un hombre, en este mundo del Génesis. La primera ciudad (p. 187).

La fundación, la construcción de una ciudad, las primeras personas que la habitaron, quiénes eran, de dónde venían, qué nombre dieron a dicho espacio, cuáles son sus leyes y sus límites; todos estos son interrogantes que aparecen insistentemente como una demanda de saber, demanda que en primer término se le hace a la historia. Pese a que la ciencia histórica elabora tratados acerca de pueblos indígenas, descubrimientos, conquistadores, colonizadores, entre otros, los ubica en fechas precisas, y sitúa los acontecimientos en un orden lineal y, en apariencia, coherente, la pregunta fundamental continúa latente. Mientras sociólogos y antropólogos buscan responder a estos interrogantes al describir comportamientos, costumbres y poblaciones, la pregunta por el origen va más allá de toda respuesta objetiva, pues se escapa a los designios de la razón y de la historia. Son cuestiones que acompañan al ser humano desde sus principios y lo enfrentan con su propia muerte, están en el lugar de lo indecible, de lo que solo consigue 
ser rodeado por lo simbólico, y por ello las entendemos como preguntas primordiales. Estas requieren de la simbolización para dar un sentido al vacío que evidencian, necesitan de la cultura y sus construcciones colectivas como la mitología, la religión, la magia y el arte:

El relato épico y la novela, como los demás géneros literarios, prolongan en otro plano y con otros fines la narración mitológica. En ambos casos se trata de contar una historia significativa, de relatar una serie de acontecimientos dramáticos que tuvieron lugar en un pasado más o menos fabuloso (Eliade, 1968, p. 209).

El mundo creado por Mejía Vallejo da una posible respuesta a esa pregunta por el origen, en tanto se ordena como espacio simbólico. El tono en el que se construye Balandú es mítico, entendiendo mito como "un sistema dinámico de símbolos, arquetipos y esquemas; sistema dinámico, que bajo el impulso del esquema, tiende a componerse como relato" (Durand, 2004, p. 64). Para poder dar cuenta de esa pregunta por el génesis, cuyo sentido está velado para el lenguaje común, se necesita del mito en tanto relato que dispone el mundo para el misterio, que abre las posibilidades de comprender lo que subyace como inentendible. Sin que se limite a un discurso incomprensible, la potencialidad del mito radica en acercar el mundo divino al humano, pues el pensamiento mítico consigue dar claridad y sentido a la cotidianidad al traer continuamente a colación los actos que se llevaron a cabo en el origen. Balandú, "pueblo en vía de sueño" (Mejía Vallejo, 1994, p. 16), se estructura como un mundo mítico: el lugar donde suceden los hechos primeros y se divisa el destino de las personas que viven en la montaña, una geografía que delimita los movimientos al cargar simbólicamente el mundo sensible. Entendemos, según las teorías que venimos revisando, que el espacio, así concebido, se expresa como lugar de actuación, una metáfora de considerable potencial semántico que varía según los contextos y las relaciones que en ellos se puedan establecer, al vincularse con las diversas formas de la narración.

Balandú es un espacio atravesado por el pensamiento mágico donde la palabra y el nombre contienen al objeto mismo, su acción tiene poderes reales; así, por ejemplo, una maldición tiene efectos al ser pronunciada y al evocar un muerto este recobra existencia. Desde la primera descripción de la ubicación de Balandú, entramos en un tiempo remoto:

En lo más alto de la cordillera que corresponde a Balandú hay un páramo de vegetación escasa y extraña. Enormes piedras soltadas por una explosión —que destruyó el mismo volcán que la produjo - ayudan a esta imagen de abrupta soledad y apretado abandono (Mejía Vallejo, 1994, p. 15). 
El tiempo de la explosión, de los primeros momentos de la cordillera, el del nacimiento de la flora del páramo, al hacerse relato se insertan en un tiempo fabuloso que, al decir de Mircea Eliade (1968), lo hace a uno contemporáneo de los hechos y de los seres que se evocan: "En una fórmula sumaria, se podría decir que, al 'vivir' los mitos, se sale del tiempo profano, cronológico y se desemboca en un tiempo cualitativamente diferente, un tiempo 'sagrado', a la vez primordial e indefinidamente recuperable" (p. 30). El tiempo de los orígenes, del mito, en el que todo ocurrió por primera vez, es un "tiempo fuerte", un tiempo sagrado en el que algo nuevo y altamente significativo se manifestó. El deseo de volver al primer momento en el que todo se hizo es constante en los seres humanos, de ahí la necesidad de crear mundos que le permitan este retorno. Al dar origen a un mundo, el individuo habita un espacio, "cosmiza el Caos", organiza su hábitat a partir de la nostalgia de vivir el tiempo de los dioses, de los ancestros, de la necesidad de experimentar nuevamente la reconstrucción del cosmos tal como era in illo tempore.

Partir del momento originario y desde ahí construir un universo garantiza que el mito pueda presentarse como una respuesta para comprender la realidad. Siguiendo a Eliade (1968), entendemos que "gracias al mito, el Mundo se deja aprehender en cuanto Cosmos perfectamente articulado, inteligible y significativo. Pues al contar cómo fueron hechas las cosas, los mitos revelan por quién y por qué lo fueron y en qué circunstancias" (p. 163). Esta explicación de motivos y hechos entrega una información sobre el origen que tiene un sentido de "revelación", es decir, nos entrega una verdad, como se hace en este fragmento donde un elemento del paisaje se torna imagen poética:

-Y ese Balandú tuyo, ¿dónde queda?

-Entre la neblina.

-Eso no es una dirección.

-Es la dirección de Balandú, el país de la niebla.

La que sube por los arroyos, la que baja por los páramos, la que rodea a cada persona, la que va dejando el recuerdo. La del olvido cuando se pierde el amor en otras nieblas, las que al evaporarse dejan los llantos solos (Mejía Vallejo, 2002a, p. 90).

La acción reveladora del mito nos lleva a pensar en la fuerza simbólica de la palabra. La palabra, al evocar, crea una imagen y "la imagen se sustenta a sí misma, sin que le sea necesario recurrir ni a la demostración racional ni a la instancia de poder sobrenatural: es la revelación de sí mismo que el hombre se hace de sí mismo" (Paz, 1956, p. 137). Es con la imagen reveladora que se construye el espacio mítico, nombrar es dar existencia, construir mundos imaginarios, es el efecto de la palabra poética que "siempre nos lleva más allá, a otras tierras, a otros cielos, a otras verdades” (p. 190), reflejo de nuestra 
verdad. Esa imagen reveladora es entregada por Mejía Vallejo (1984) cuando integra el espacio con estados del alma: "Si miras un llanto frente a una boca que ríe, campanas al fondo, eso es Balandú; si notas que el amor te hiere y se estanca en el corazón olvidado, eso es Balandú” (p. 50).

Así, la palabra destinada a responder las preguntas más profundas del género humano actúa como epifanía, conectándose con la experiencia de lo sagrado. Dice Octavio Paz (1956) que "toda aparición implica una ruptura del tiempo y del espacio: la tierra se abre, el tiempo se escinde [...] El vértigo brota de ese abrirse el mundo en dos y enseñarnos que la creación se sustenta en un abismo" (p. 138). Aparece aquí una paradoja que da cuenta de la imposibilidad de alcanzar el sentido total del símbolo, pues la imagen que revela y presenta lo interior escondido, al hacerlo, nos pone frente a un abismo que vuelve a mostrarnos que hay algo que quedó por fuera de la significación y abre de nuevo una pregunta, que conlleva la necesidad de otros símbolos que vuelvan a repetir la epifanía:

Mediante ese poder de repetir, el símbolo satisface de manera indefinida $\mathrm{su}$ inadecuación fundamental. Pero esta repetición no es tautológica, sino perfeccionante, merced a aproximaciones acumuladas. A este respecto es comparable a una espiral, o mejor dicho a un solenoide, que en cada repetición circunscribe más su enfoque, su centro. No es que un solo símbolo no sea tan significativo como todos los demás, sino que el conjunto de todos los símbolos relativos a un tema los esclarece entre sí, les agrega una "potencia" simbólica complementaria (Durand, 1971, p. 17).

Se manifiesta así el proceso de creación y de recreación, en el que imágenes diferentes aparecen con un mismo sentido. Momento del retorno arquetípico que demuestra que las preguntas primordiales solo consiguen resolverse temporalmente por medio del mito, que actúa como la memoria arcana. La "imagen simbólica que necesita ser revivida sin cesar, casi como un trozo musical o un héroe teatral requiere de un 'intérprete" (Durand, 1971, p. 38), es este el lugar del escritor. Balandú es la revivificación de una imagen que podemos recorrer desde los tiempos antiguos de la Arcadia o de la Atlántida hasta el Nuevo Mundo, ese territorio innominado que actúa como imagen simbólica y necesita de intérprete. El arquetipo se construye a partir de diversas representaciones de un mismo motivo, estas varían sus detalles y manifestaciones manteniendo un tema básico que actúa como el núcleo desde donde se reordenan los sentidos. Nuestro pueblo imaginario responde a un esquema arquetípico, el de la ciudad de donde surge todo, el espacio que explica las formas existenciales de un grupo humano. Por esta razón, en las historias relatadas en Balandú podemos observar cómo 
se retoman espacios simbólicos que son comunes en la literatura, como la casa, la cantina, la montaña, el camino o el río. Y cómo estos, a su vez, se recrean en temas con resonancias esquemáticas y arquetípicas semejantes al enfrentamiento al padre, la estirpe maldita, el hombre que sale de su casa en busca de su destino y se enfrenta a la aventura o la mujer que está a la espera de un momento que defina su vida:

Aires de encierro, complicidad en la angustia, historias sombrías, uniones sobresaltadas en el remordimiento. Las frases mostraban esa reserva que el frío y el temor grababan en rostros y maneras. Todo era insinuación forzada, con la bruma cubridora del páramo: hasta las imágenes conservaban algo de aparecido en la noche lenta: un puma que no podía morir, plantas ambulantes, aves de un pico en cada pluma de su ala colectiva, nubáceos descendidos de las nubes más espesas, núa-núas y bisabisanes (Mejía Vallejo, 1994, p. 15).

El universo literario de Mejía Vallejo explica el origen de los pueblos andinos, y particularmente de Antioquia, al hacer uso de símbolos universales empleados una y otra vez para responder a este tipo de interrogantes. Al ser un retorno de la epifanía, Balandú se reconoce en la tradición simbólica, de la cual comparte con otros mundos su estructura, esa que lo hace mítico, y se diferencia en aquello que corresponde concretamente a la historia antioqueña. Vemos entonces cómo esta rememoración del momento original, donde ya hemos divisado la raíz arquetípica, tiene un halo histórico, que es quizá lo que hace variar los detalles de un momento a otro. En ese recuento de hechos históricos, "lo importante es rememorar incluso los detalles más insignificantes de la existencia (presente o anterior), pues es únicamente gracias a este recuerdo como se consigue 'quemar' el pasado, dominarlo, impedir que intervenga en el presente" (Eliade, 1968, p. 103). Pero, como ya hemos dicho, la función mítica no es la de historiar, en el sentido de relatar los hechos tal cual sucedieron. El mito, al ser palabra simbólica, palabra poética, cuenta los acontecimientos que fueron y los que no fueron, y su misión es la que Octavio Paz (1956, p. 191) le da al poeta: decir, revelar la condición humana al consagrar un instante. De ahí que Balandú no sea reflejo de un momento cronológico, sino revelación constitutiva de las significaciones de dicho momento y en tanto esto responde al origen desde la imaginación simbólica.

\section{Balandú, el mito y la memoria}

El relato mítico es una forma de la memoria, "poder de organización de un todo a partir de un fragmento vivido" (Durand, 2004, p. 409). A través de él se recurre a los recuerdos personales, colectivos o incluso históricos, para 
ordenar la narración en la que se cuenta quiénes somos. Dejar constancia de la significación de estos momentos hace que se perpetúen, es decir, solo si estos momentos adquieren una dimensión ejemplar y dejan de ser sucesos netamente individuales, perdurarán. Por ello, siguiendo a Eliade (2013), podemos afirmar que en lo mítico solo se recuerda el arquetipo, que se conserva en la memoria colectiva, pues el recuerdo de sucesos y personajes "es modificado al cabo de dos o tres siglos a fin de que pueda entrar en el molde de la mentalidad arcaica, que no puede aceptar lo individual y solo conserva lo ejemplar" (p. 60). El arquetipo, al ser una estructura dinámica, permite el cambio con el paso del tiempo a la vez que mantiene una constante que deja por fuera particularidades históricas y personales. Al decir que el relato mítico es memoria y que esta necesita del arquetipo, entendemos que la memoria está "lejos de ser una intuición del tiempo, escapa a este en el triunfo de un tiempo 'recuperado', por lo tanto negado", así "la memoria — como la imagen — es esa magia supletoria por la cual un fragmento existencial puede resumir y simbolizar la totalidad del tiempo recobrado" (Durand, 2004, p. 408), es decir, al eternizar lo arcano la memoria niega la muerte.

La importancia que se le da al recuerdo en los mundos míticos es muestra de la preocupación que los pueblos latinoamericanos han tenido en relación a permanecer en el tiempo, a no morir. Y así como los textos, por su carácter mítico, levantan una memoria de las poblaciones, al mismo tiempo reflejan la preocupación por el olvido que se vivencia como un esquema básico de la cultura. Revisemos en Cien años de soledad, específicamente en la consolidación de Macondo, un evento que metaforiza lo que venimos argumentando: la peste del olvido. Este episodio pone en riesgo a toda la aldea, su interacción con las cosas, su utilidad, pero sobre todo sus relaciones interpersonales, su parentesco, pone en peligro su condición humana. También en el pueblo de la cordillera que es Balandú observamos que la narración es una constante evocación, en todo momento los personajes recuerdan, evocan su pasado, sus muertos no se van porque son convocados, se quedan en los espejos, en el rumor del río, en los álbumes de fotografías que actúan como una actualización de los acontecimientos: "Allí sacábamos los recuerdos al sol, nos quedábamos mirándolos al sol, nos quedábamos mirándolos en silencio [...] Los recuerdos no se habían hecho enemigos todavía" (Mejía Vallejo, 1994, p. 110). En Balandú no se quiere olvidar, el miedo de no recordar es el miedo a la muerte, a la desaparición última, a que el nombre propio pierda sentido para el mundo y para la estirpe a la que se pertenece: 
Sentirse recuerdo, saberse únicamente posibilidad de un recuerdo, de tres recuerdos y cerrar el cielo y clausurar las respiraciones verdaderas.

- Hablamos para no olvidar que estamos muertos y creer que alguna vez existimos. ¿Qué se conservará cuando yo muera? Tal vez caerá en la noche una mazorca, una iguana dormida meterá un brinco extraño bajo cualquier piedra, tal vez relinche un caballo. La vida es trampa que nos tiende la muerte (Mejía Vallejo, 1980, p. 145).

La vida de la familia Herreros, fundadora y pobladora de Balandú, se narra como una memoria que trasciende la concatenación de sucesos. El tiempo del relato es ahistórico, no hay un orden cronológico consistente, más bien remite a un devenir rítmico entre una forma temporal y otra. De esta manera, "la totalidad del tiempo queda dividida por ciertas barreras semejantes a las barras musicales; pero estos intervalos resultantes, en un principio son meramente percibidos y no medidos o contados" (Cassirer, 1972, p. 145). La familia hace memoria de sí misma en relación a momentos muy precisos de su pasado, una especie de periodos: el tiempo de la primera maldición, el de la maldición de Efrén, el de la guerra de los Mil Días, el de la Casa de las Cadenas, el de la residencia en la casa del páramo. Cualquiera de estos momentos puede asumir el lugar del comienzo o del final, cada periodo reubica a los otros en el pasado o en el futuro, manteniéndose una impresión de estar en un presente constante, en una eternidad. Porque el tiempo es rítmico en tanto se moviliza a partir de las cargas simbólicas de los momentos y no de la cronología histórica. De esta manera la familia se explica la realidad a partir de esos periodos, ya que cada uno de ellos tiene un sentido, a manera de rituales en los que los personajes logran encontrar su verdadera esencia:

Yo moriré y será como si alguien recordara mi muerte, con recuerdo de lo sucedido una vez. Alguien que nunca pierde su maldita memoria. Volveré a cantar después de que me vaya, escucharán los que me recuerden. Tal vez el recuerdo en otros sea la vida que quedará a los muertos (Mejía Vallejo, 1980, p. 14).

En la memoria de los Herreros hay una mitificación de la existencia, en la cual Balandú, la tierra que los ve nacer, donde todo sucede, de la que quieren huir y a la que deben retornar, es el centro. Se regresa a la Casa de las dos Palmas para recordar, para que la memoria se pueda considerar efectiva, verdadera en el sentido de recuperación de la existencia que se escapa: "El regreso a la tierra era su destino; pero una tierra donde pudieran sentirse acompañadas sus fuerzas. Y solas, con otra soledad de las alturas" (Mejía Vallejo, 1988, p. 25). En las novelas no se cuenta una leyenda de la vida y muerte de la familia Herreros, lo que se relata es el destino de esta familia, como en el caso del héroe que realiza empresas ejemplares que le permiten 
perdurar en el tiempo, y que por ser impersonales son arquetipos. La unión con los muertos está presente en toda la saga como una forma de mantener la familia viva, los difuntos son evocados una y otra vez en relatos que se van puliendo hasta alcanzar las características de esas narraciones ejemplares. Este intento constante de sostener la presencia de quienes ya no están se convierte por momentos en una tiranía que somete a los vivos a soportar una carga difícil y asfixiante, aunque necesaria existencialmente:

-Las almas de los muertos.

-son animales oscuros

-son animales invisibles

-que se alimentaron de nuestra desesperación.

- Inventamos tanta angustia

- para no dejarnos desaparecer.

-Para no dejarnos morir.

Como siluetas, como recuerdos en busca de su dueño, como sueños extraviados. Sensaciones de cuando quiso abandonar aquellos objetos familiares, aquellos olores de tierra húmeda y trigo asoleado y ciudad nocturna y gente dolida y esperanzada en esa imprecación.

-Cuando acaba nuestra capacidad de sufrimiento,

-cuando han secado nuestras almas,

-se llevan lo que fuimos.

-Son hienas malditas.

-Peores que los dioses (Mejía Vallejo, 2002b, p. 182).

Resulta evidente la relación que se establece entre las preguntas por el principio y el fin. Al rastrear la manera como Balandú se hace espacio mítico y explica el origen, es inevitable hablar de las preocupaciones por la memoria, el olvido y, finalmente, por la muerte. La mitificación que se hace a través de un mundo ficcional se rige por la función esperanzadora de la imaginación simbólica en la que, según Durand (1971), se niega éticamente lo negativo, al ser esta la función de eufemización, no una mera "máscara con que la conciencia oculta el rostro horrendo de la muerte, sino, por el contrario, dinamismo prospectivo que, a través de todas las estructuras del proyecto imaginario, procura mejorar la situación del hombre en el mundo" (p. 127). No quiere decirse con ello que los relatos míticos requieran de finales felices, pues se trata, más bien, de dar sentido al destino mortal del ser humano:

La novela moderna, como la tragedia griega, celebra el misterio de la destrucción, que en el tiempo es la vida. El final feliz es satirizado justamente como una falsedad; porque el mundo tal como lo conocemos, tal como lo hemos visto, no lleva más que a un final: la muerte, la desintegración, el desmembramiento y la crucifixión de nuestro corazón con el olvido de las formas que hemos amado (Campbell, 1972, p. 31).

Los grandes relatos se escriben para devolver la fe, para instaurar la esperanza en los momentos en los que el viejo orden se desmorona y la 
percepción de la realidad es confusa y caótica. El retorno a la esperanza es posible a través del hallazgo de nuevas formas de simbolización, del retorno de sentidos que expliquen el cosmos, de ahí que la función del artista sea la mitologización de lo cotidiano; lo poético que atraviesa la creación artística es necesario para mantener vivo el mito. El arte es el espacio propicio para que, como decía Camus, la imaginación reanime los mitos, para dar lugar a una memoria simbolizada que trascienda los hechos y renueve los saberes primeros, esos que se consolidaron en los días del tiempo originario, esos que si se olvidan sepultan a una sociedad, las palabras fundadoras. Como lo expresa el narrador de la saga de los Herreros: “¿No tenía derecho a componer el presente y abrir una brecha de imaginación a lo que debía seguir? / - $\mathrm{Si}$ no hay imaginación, tampoco hay realidad" (Mejía Vallejo, 2002b, p. 256).

\section{Conclusión}

Balandú, ese gran proyecto de Mejía Vallejo, se consolida como espacio simbólico en la medida que alcanza las resonancias del mito, nombra el origen y posiciona los símbolos primeros, es un canto sobre la contienda del hombre que abrió la montaña andina y fundó aldeas, sintió suyos los ríos y los montes, y los entregó en herencia a sus hijos. Además, es un relato detallado de temores, costumbres cerradas que generan infortunios, vicios que dan matices a la vida y arrastran a la perdición, son cuentos de relaciones apasionadas, de amores tranquilos, de esperas sin presentimientos de cambio, de arraigos a una tierra que se deja atrás para abrirse futuro: "Casa de las dos Palmas, páramos de Balandú. Allá regresaba, los ojos amplios para abarcarlo todo" (Mejía Vallejo, 1994, p. 120). Esta aldea andina expresa la preocupación de un continente por nombrarse, por reconocer sus formas $y$ contornos, muestra la necesidad de levantar un memoria de características particulares que recoja uno a uno los sentidos ancestrales, los contemple con detenimiento para volverlos a convertir en imágenes simbólicas, para no dejar de existir en la palabra de los que están por venir. Balandú nos devuelve la esperanza del mito, que no es vana ilusión de un mundo sin dificultades, sino que consigue rodear con símbolos a la muerte. Este tipo de aldeas infunden valor para pararse frente al abismo de los significantes humanos que nos muestran el fin, ayudándonos a sobrellevar la sensación de vacío, haciéndonos partícipes de rituales, historias y danzas. Al sumergirnos en la lectura de Balandú reemprendemos la labor de su autor como si nos sentáramos en el telar para continuar moviendo los hilos, entramando los 
colores para tejer una imagen que consiga nombrar lo más íntimo, que retorne hasta los días primeros y vuelva a traer la palabra del mito refrescada con una nueva belleza. Balandú, como creación artística, es revivificación del mito, ensoñación en cuyo fondo poético resuenan los ecos del saber originario.

\section{Referencias bibliográficas}

1. Campbell, J. (1972). El héroe de las mil caras. Psicoanálisis del mito. México: Fondo de Cultura Económica.

2. Carpentier, A. (1971). Los pasos perdidos. Barcelona: Seix Barral.

3. Cassirer, E. (1963). Antropología filosófica: introducción a una filosofía de la cultura. México: Fondo de Cultura Económica.

4. Cassirer, E. (1972). Filosofia de las formas simbólicas II: el pensamiento mítico. México: Fondo de Cultura Económica.

5. Cortázar, J. (1994). Situación de la novela [1950]. En J. Alazraku (Ed.). Julio Cortázar. Obra crítica 2. Madrid: Alfaguara.

6. Durand, G. (1971). La imaginación simbólica. Buenos Aires: Amorrortu Editores.

7. Durand, G. (2004). Las estructuras antropológicas del imaginario. México: Fondo de Cultura Económica.

8. Eliade, M. (1968). Mito y realidad. Madrid: Guadarrama.

9. Eliade, M. (2013). El mito del eterno retorno. Madrid: Alianza Editorial.

10. Mejía Vallejo, M. (1980). Tarde de verano. Bogotá: Plaza \& Janés.

11. Mejía Vallejo, M. (1984). Y el mundo sigue andando. Bogotá: Planeta.

12. Mejía Vallejo, M. (1988). La Casa de las dos Palmas. Bogotá: Planeta

13. Mejía Vallejo, M. (1994). Las noches de la vigilia. Medellín: Universidad Pontificia Bolivariana.

14. Mejía Vallejo, M. (2002a). La sombra de tu paso. Medellín: Biblioteca Pública Piloto.

15. Mejía Vallejo, M. (2002b). Los invocados. Medellín: Biblioteca Pública Piloto.

16. Paz, O. (1956). El arco y la lira. México: Fondo de Cultura Económica. 